\title{
Drilling Optimization of Tight Sands and Shale Gas Reservoir in Jambi Sub-Basin Based on Pore Pressure Estimation Using Drilling Efficiency Mechanical Specific Energy (DEMSE) and Bowers Methods
}

\author{
Benny Abraham Bungasalu 1, M. Syamsu Rosid 1,*, and Don S. Basuki ${ }^{2}$ \\ ${ }^{1}$ Department of Physical Science, Faculty of Natural Science and Mathematics, University of Indonesia, Depok - Indonesia \\ ${ }^{2}$ PT. Pertamina (Persero), Jakarta-Indonesia
}

\begin{abstract}
The subsurface pressure analysis is used to detect the overpressure and problems in the well that will be drilled based on exploration well data. Various problems were found while drilling operations carried out on A and B wells, namely, Kick and Pipe sticking which cause a high NonProductive Time (NPT). This research is conducted to identify the mechanism of overpressure formation in Tight Sand Gas and Shale Gas in the Jambi Sub-Basin. Furthermore, to predict pore pressure using the Drilling Efficiency and Mechanical Specific Energy (DEMSE) and Bowers method. The final result will be a 3D pore pressure cube in the area based on quantitative analysis of post-stack seismic inversion. The results of the pore pressure analysis from the wells and the 3D pore pressure model indicate that top of overpressure occurs in the Gumai Formation, then it is decreasing gradually approaching the hydrostatic pressure on the Basement. The mechanisms of overpressure are caused by under compaction, fluid expansion (kerogen maturation). The Gumai Formation and Talang Akar Formation are shale rocks so the type of mud weight that is well used is oil based mud (OBM).
\end{abstract}

Keywords: Overpressure; Bowers method; DEMSE method.

\section{Introduction}

Accurate pore pressure estimation is needed in all aspects of oil and gas exploration and development. The subsurface pressure analysis is carried to determine the mud weight optimum. It is used to maintain the stability of the borehole which is influenced by the strain around it. Pore pressure prediction using the Bowers method is better than the Eaton method because it can predict high pore pressure values and the Bowers method is considered more capable of predicting the optimal mud weight value for drilling at that depth [1]. Drilling Efficiency and Mechanical Specific Energy (DEMSE) method is better than the Dxc method to determine pore pressure, because the Drilling Efficiency and Mechanical Specific Energy (DEMSE) method is not only considering drilling speed, rotation speed, size drill bit, up to the specific gravity of the mud in determining pore pressure but also adding Torque value [2].

The necessity of oil and gas from fossil energy sources in Indonesia is increasing, while the oil and gas reserves produced from conventional reservoirs are decreasing. To anticipate gas shortages, it is necessary to explore new resources especially unconventional resources such as shale gas.

The South Sumatra Basin consists of five sub-basins namely the Jambi Sub-Basin, North Palembang Sub-
Basin, Central Palembang Sub-Basin, South Palembang Sub-Basin, and Bandar Jaya Sub-Basin. The location of the study on the X field located in the Jambi sub-basin. The South Sumatra Basin regional stratigraphy is shown in Fig. 1 [3]. From the old to the young are Basement, Lahat Formation, Talang Akar Formation, Baturaja Formation, Gumai Formation, Air Benakat Formation, Muara Enim Formation, and Kasai Formation. The focus of this study is the Talang Akar Formation. This formation is dominated by sandstone at the bottom and claystone at the top. It is deposited incongruously above the Lahat Formation that divided into 2 members, namely GRM (grit sand member) which is composed of rough clastics with shale inserts and coal, and TRM (transitional members) which is composed shale. The deposition environment of the Talang Akar Formation is in the littoral to the shallow marine environment, which is in the late Oligocene - Early Miocene. The thickness of the formation varies between 100 - 500 meters. The contact between the Talang Akar Formation and Telisa and the Telisa Limestone Basal members is conformable. The contact between Talang Akar and Telisa is difficult to pick from wells in the trough area because the lithology of these two formations is generally the same.

* Corresponding author: syamsu.rosid@ui.ac.id 


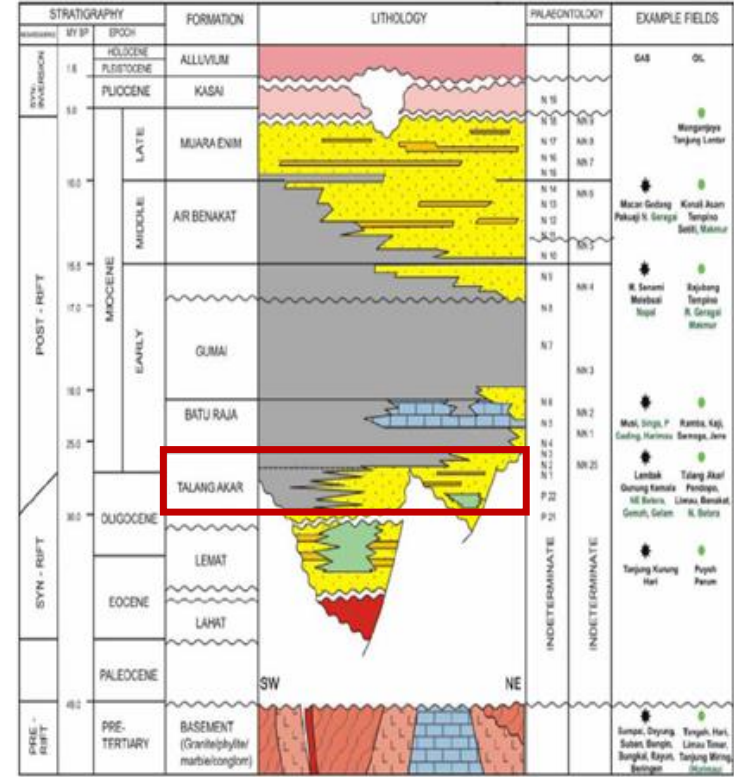

Fig. 1. Stratigraphy of the South Sumatra Basin [3]

\section{Method}

\subsection{Geopressure}

Pore pressure is pressure caused by fluid inside the formation pores of the rock. Hydrostatic pressure is the pressure caused by the weight of the column formation water. Overburden pressure is pressure exerted to a rock by overlaying sediments, water, and air above it. Generally, the overburden pressure will increase while depth increase as well. Fracture pressure is the total of the pressure that the formation can hold before a formation damaged and destroyed. The prediction of fracture pressure must be smaller or equal to the overburden pressure and greater than the pore pressure (pore pressure).

\subsection{Overpressure Formation Mechanism}

The mechanism of overpressure can be caused by two mechanisms, namely the mechanism relating to loading and a mechanism that not related to the process of loading (unloading) [4]. The mechanism of loading is related to overburden pressure due to the sedimentation process that takes place faster than normal conditions. This rapid sedimentation process causes the fluid inside the rock pore to not be able to get out and be trapped during the burial. Consequently, the pore pressure in the rock increases and the sediment in a compact failure/disequilibrium compaction condition. The unloading mechanism occurs due to an increase in the mass of fluid inside the rock pore. Overpressure formed through this mechanism is characterized by a reduction in the effective stress value of rocks.

Based on the cross plot between density and velocity to detect the mechanism of overpressure which is described by [5] that in the blue plot shows the density increases, the velocity increases too. It shows the mechanism of overpressure is caused by disequilibrium/normal compaction. Brown plot reveal at certain densities with a constant value, velocity has drastically decreased as depth increasing as well. This explains the mechanism of overpressure caused by fluid expansion. The green plot shows that the density increases but the velocity decreases which indicates that the overpressure mechanism is caused by a hybrid chemical. The last, the red plot explains that the velocity is constant and the density increases which indicates that the mechanism of overpressure is caused by chemical compaction/clay diagnosis.

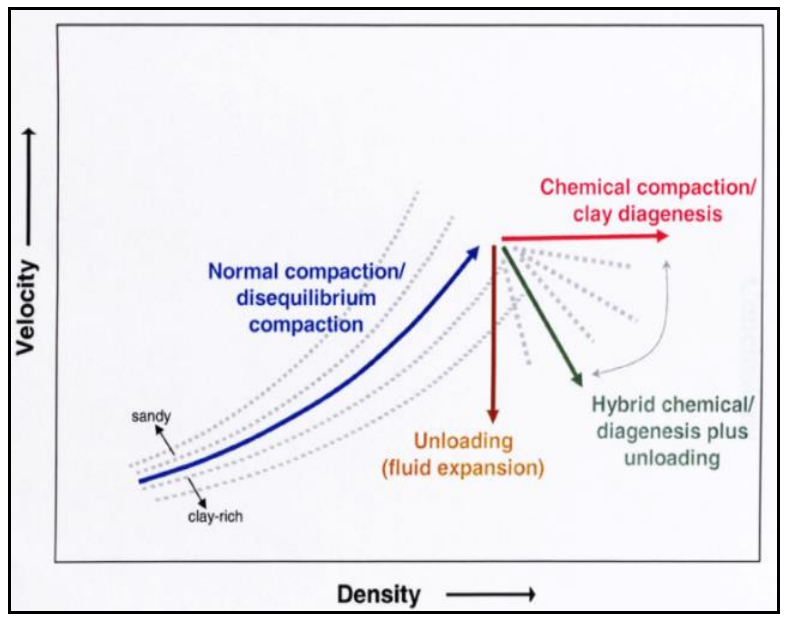

Fig. 2. Pattern of cross-plot density with velocity to detect overpressure mechanisms [5].

\subsection{Pore Pressure Prediction}

\subsubsection{Drilling Efficiency and Mechanical Specific Energy (DEMSE) Methods}

Mechanical Specific Energy (MSE) is Energy required to destroy a unit volume of rock [2]. The DEMSE (Drilling Efficiency and MSE) method to predict pore pressure is introduced by [2].

$$
\begin{aligned}
& M S E=\frac{480 \times T \times R P M}{d b i t^{2} \times R O P}+\frac{4 X W O B}{\pi d^{2}{ }^{2} t^{2}} \\
& D E=\frac{\text { Rock strength (insitu) }}{\text { Energy required to break }}=\frac{\text { CCS }}{M S E} \\
& D E_{\text {trend }}=\mathrm{a} \varphi_{\mathrm{n}}^{\mathrm{b}} \\
& P=P_{n}+\Delta D E \times M S E \times\left\{\frac{1-\sin \theta}{1+\sin \theta}\right\} \\
& P=E C D-\left(D E_{\text {tren }} x M S E-U C S\right) \times\left\{\frac{1-\sin \theta}{1+\sin \theta}\right\} \\
& C C S=U C S+\Delta P\left[\frac{1+\text { IN } \theta}{1-\text { SIN } \theta}\right] \\
& \mathrm{UCS}=0.43 V p^{\mathrm{a.2}} \\
& \theta=1.532 V p^{0.5148}
\end{aligned}
$$

where:

MSE = Mechanical Specific Energy, psi 
$T=$ Torque, $\mathrm{ft} . \mathrm{lb}$

$R P M=$ Drill string rotation speed, RPM

$d b i t=$ Bit diameter, in

$W O B=$ Weight on Bit, lbs

$R O P=$ Rate of Penetration, $\mathrm{ft} / \mathrm{hr}$

$D E=$ Drilling Efficiency

$C C S=$ Confined Compressive Strength, psi

$U C S=$ Unconfined Compressive Strength, psi

$E C D=$ Equivalent circulation density, psi

$\theta=$ Angle of internal friction

\subsubsection{Bowers Method}

The Bowers method basically uses a concept similar to the Eaton method, which is an equation to determine the Effective Stress value [6]. However, the equation expressed by Bowers is better than Eaton, because the Bowers equation more considers the unloading factor. Therefore, the Bowers method more suitable for predicting formations that have high pore pressure values with loading and unloading mechanism. The Bowers method to predict pore pressure is introduced by [6] as:

$$
\begin{aligned}
& V=5000+A \sigma^{B} \\
& V=5000+A\left[\sigma_{\max }\left(\frac{\sigma}{\sigma_{\operatorname{sax} x}}\right)^{\frac{1}{W}}\right]^{\sigma} \\
& \sigma_{\max }=\left(\frac{V_{\max x}-5000}{A}\right)^{\frac{1}{B}}
\end{aligned}
$$

Where:

$V=$ Velocity $(\mathrm{Ft} / \mathrm{s})$,

$\sigma=$ Effective pressure (Psi),

$\sigma \max =$ Maximum effective pressure (Psi),

$A$ and $B=$ Bowers empirical coefficient

\subsection{Seismic Inversion}

Seismic inversion is a technique to create subsurface geological models using seismic data as input and well data as controls [7]. After performing a seismic inversion, an acoustic impedance cross section can be produced. Where acoustic impedance is the ability of a rock to pass through an acoustic wave. The acoustic impedance value is empirically formulated as:

$$
A I=\rho \times V_{p}
$$

Where:

$A I=$ Acoustic impedance $\left(\mathrm{Kg} / \mathrm{m}^{2} \mathrm{~s}\right)$,

$\rho=$ density $\left(\mathrm{Kg} / \mathrm{m}^{3}\right)$,

$V_{p}=\operatorname{Velocity}(\mathrm{m} / \mathrm{s})$.

Acoustic impedance values are influenced by lithology, porosity, fluid content, depth, pressure, and temperature.

\section{Research Methodology}

The methodology to determine the overpressure mechanism uses cross plot density vs. velocity and depth vs. Ro, pore pressure determination uses the Bowers method, Drilling Efficiency and Mechanical Specific Energy (DEMSE) methods by [2] and seismic data are used to build a map of distribution of estimated pore pressure using trend velocity vs pore pressure obtained from well data. From the 3D model of pore pressure, we can determine the condition of pore pressure at a certain depth according to the geological structure in the zone.

\section{Results and Discussion}

\subsection{Causes of Overpressure analysis in Well A} and $B$



Fig. 3. Cross plot between $V \mathrm{p}$ and density in well A using Hoesni plot

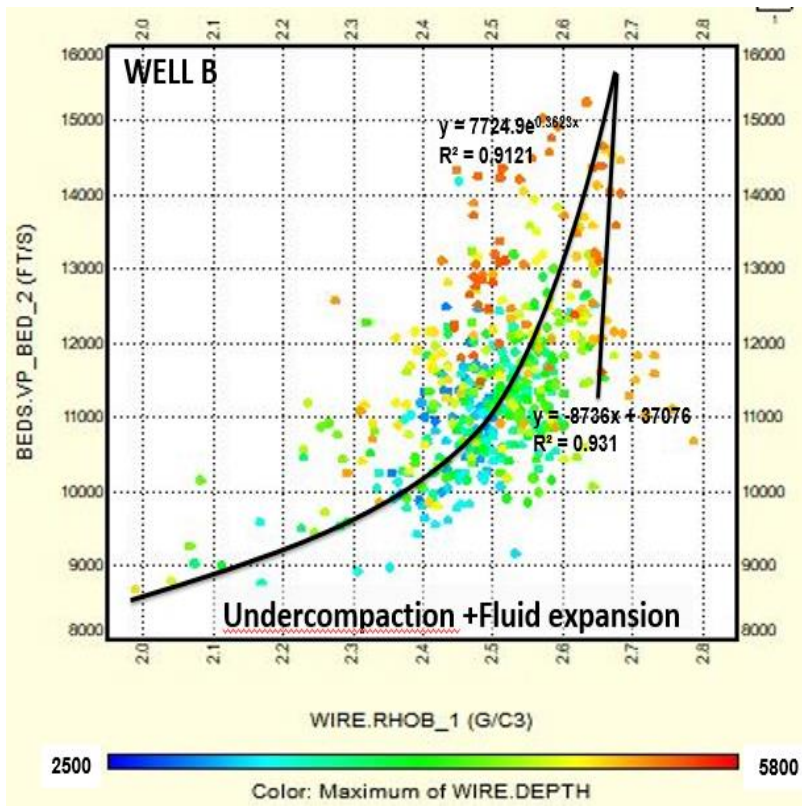

Fig. 4. Cross plot between $V \mathrm{p}$ and density in well $\mathrm{B}$ using Hoesni plot 


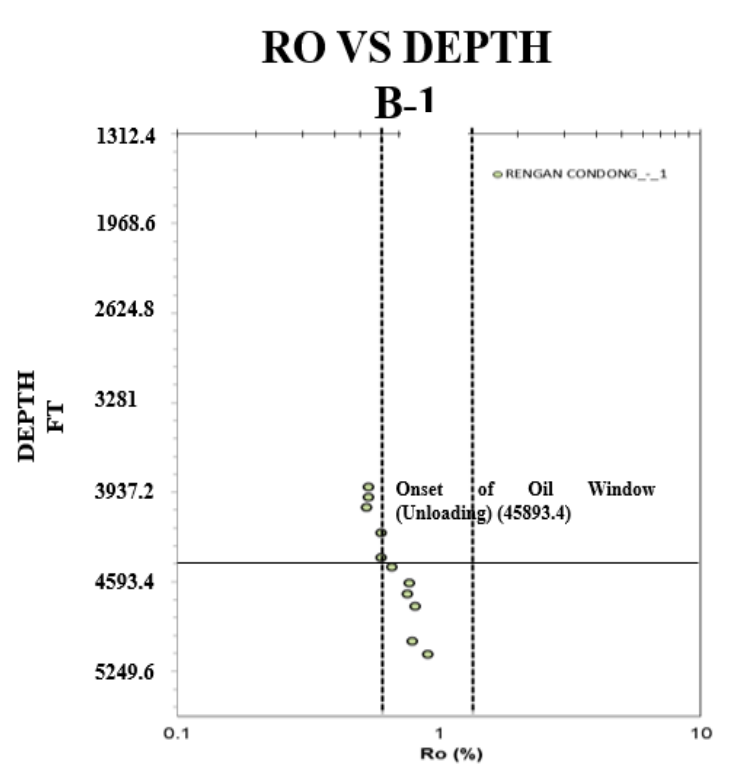

Fig. 5. Plot Depth vs. Ro at well B

Determination of the overpressure mechanism uses a sonic $\log$ cross plot analysis and density $\log$ (Hoesni plot) on well A and well B. Well A and Well B have similarity trend, that Well A shows velocity and density at 3000-4100 ft depth increases but at $5200 \mathrm{ft}-6200 \mathrm{ft}$ the velocity and density decrease. While, well $\mathrm{B}$ shows velocity and density at $4000-4800 \mathrm{ft}$ increases but at $4800 \mathrm{ft}-5400 \mathrm{ft}$ the velocity and density decrease. Based on cross plot analysis of sonic logs with log density on both well using Hoesni Plot, the mechanism of overpressure is caused by Undercompaction and fluid expansion.

Depth vs Ro analysis in well B indicates that the top of the oil window at $45893.4 \mathrm{ft}$ depth and located in the Talang Akar formation. It shows that if there is kerogen in the rock has matured and turned into a fluid (oil fluid), so the pressure increases when there is no fluid coming out and mass fluid increases from a system that causes a high overpressure. By analyzing depth vs. Ro data for B well, the overpressure formed is the unloading mechanism.

\subsection{Analysis of Pore Pressure}

The pore pressure estimation in well A using the Bowers method identified the presence of an over pressured zone at $4100 \mathrm{ft}-6600 \mathrm{ft}$. So, a good density of mud to use at $1327 \mathrm{ft}-4184 \mathrm{ft}$. is $10-14 \mathrm{ppg}$. The results of the pore pressure model are calibrated with a pressure test, so the model is made close to the actual subsurface pressure.

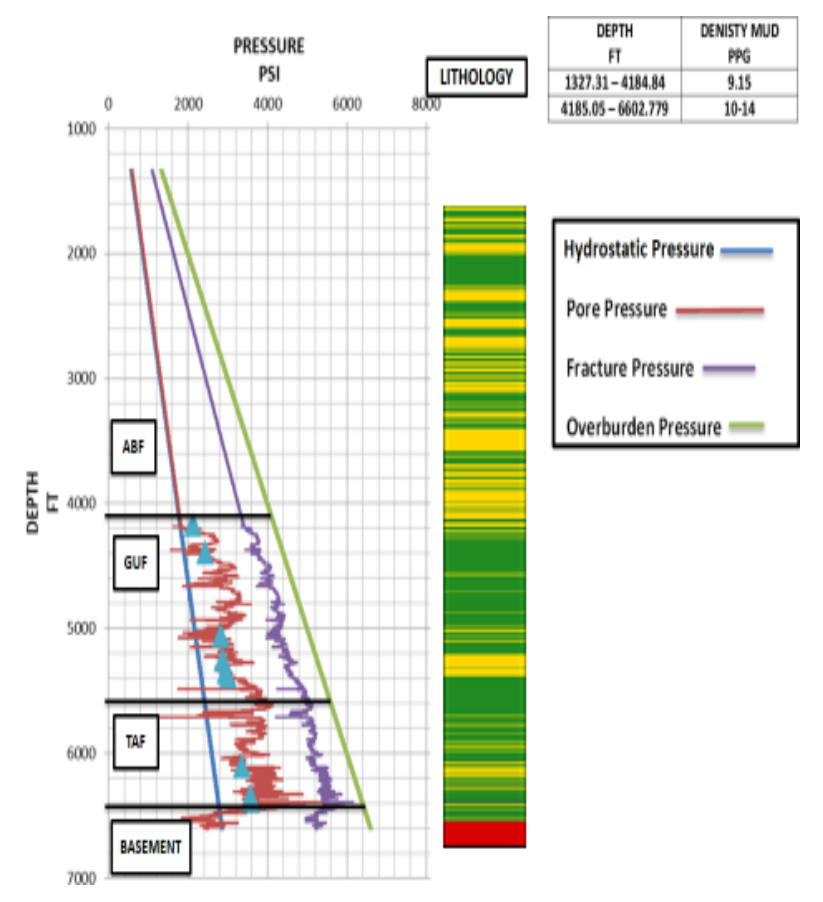

Fig. 6. Pore Pressure Profile in well A

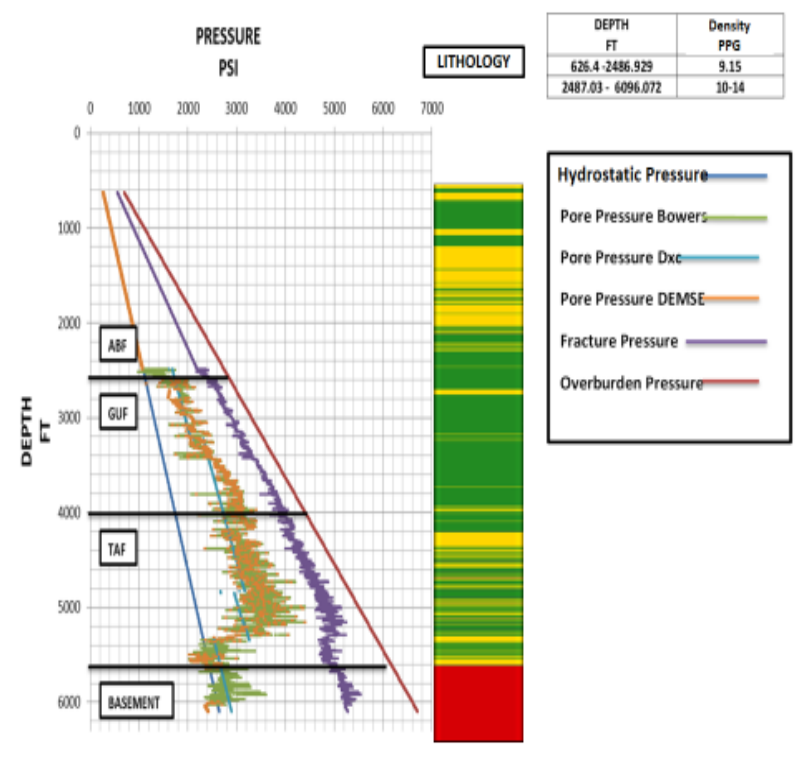

Fig. 7. Pore Pressure Profile in well B

Pore pressure estimation in well B uses Bowers and Drilling Efficiency and Mechanical Specific Energy (DEMSE) methods. The calculation results using the Bowers method and the Drilling Efficiency and Mechanical Specific Energy (DEMSE) method did not differ greatly which from the results of these calculations identified the existence of an overpressured zone at $2487.03 \mathrm{ft}-6096 \mathrm{ft}$. So, a good density of mud is used at $626.4 \mathrm{ft}-2456.9 \mathrm{ft}$ is $9.15 \mathrm{ppg}$, while $2487.03 \mathrm{ft}-6096 \mathrm{ft}$ depth is $10-14 \mathrm{ppg}$.

\subsection{Analysis of Pore Pressure Modeling}

A velocity model map is made to show the distribution of velocity values laterally which is inversely proportional to the pore pressure value from the cross 
plot velocity to pore pressure. In the Top Gumai formation model shows a low-moderate value of pore pressure while the top of the Talang Akar Formation shows a medium-high value of pore pressure. The $3 \mathrm{D}$ model is very influential to determine the density mud used in drilling planning. The Gumai formation shows a low-moderate pore pressure value. At the bottom of this formation, it is known that it is dominated by a shale layer but there are not many overpressure points in this layer (Fig. 8.). In the Talang Akar formation, the value of pore pressure is of medium-rather high value. Yellow thin layers show a rather high pore pressure value, this formation contains quite a lot of shale so that many overpressure points are detected in this formation layer (Figure 9.).

3D Model Pore Pressure Gumai and Talang Akar Formations show that overpressure in the anticline due to the presence of a mechanism of fluid expansion. Fluid expansion is kerogen in the rock has matured and turned into a fluid (oil fluid), so the pressure increases when there is no fluid coming out and mass fluid increases from a system that causes a high overpressure. Furthermore, syncline shows pore pressure caused by hydrostatic pressure. Fig. 9 shows that the Talang Akar formation is an unconventional reservoir prospect zone where high overpressure points are found due to kerogen maturation.

The formation or shale layer is a very calculated layer in determining the type of drilling mud. The shale formation is a formation consisting of rocks that contain mineral clay which can react with water in this case, namely water-based mud. The reactivity of shale can cause various problems such as swelling clay, narrowing of holes, collapsing walls which will eventually cause the pipe to be pinched when using a water based mud (WBM) type. The Gumai and Talang Akar Formations should use the oil based mud (OBM) type of mud. The use of oil based mud (OBM) has advantages such as increasing lubrication, increasing clay bonding and also being more resistant to heat without reducing sludge.

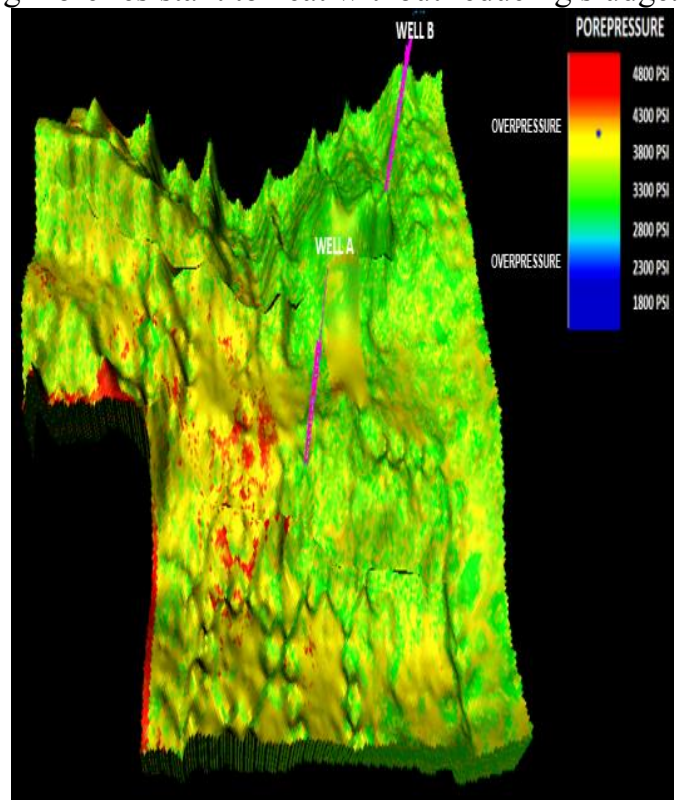

Fig. 8. 3D Model of Pore Pressure in the Gumai Formation

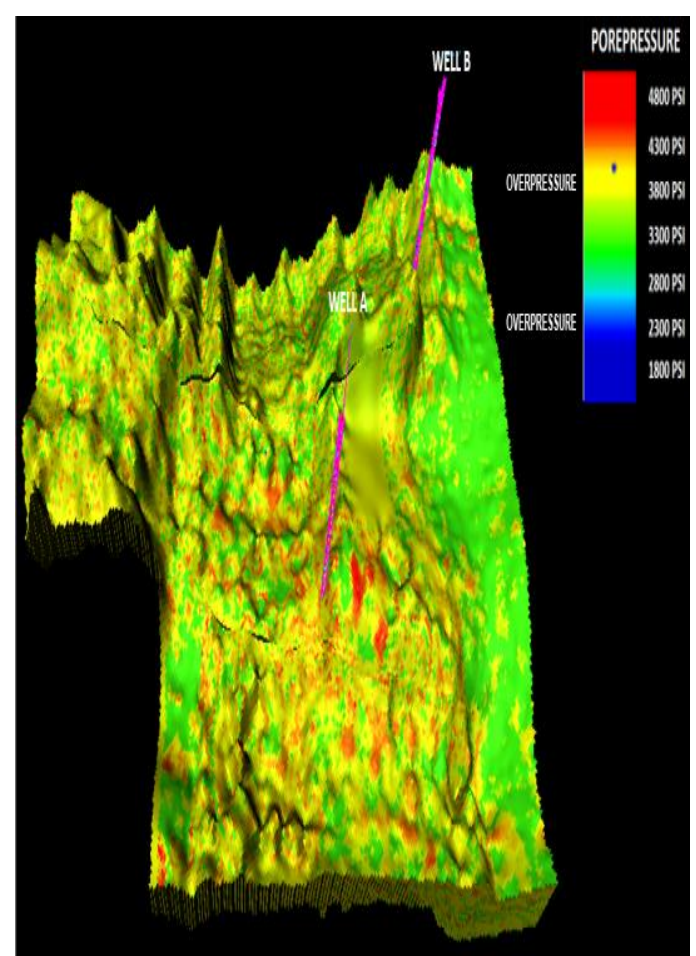

Fig. 9. 3D Model of Pore Pressure in the Talang Akar Formation

\section{Conclusion}

Based on data processing, analysis, and interpretation that has been done in this study, it can be concluded several things, namely:

a) Prediction of Pore Pressure is carried out using the Bowers method and the Drilling Efficiency and Mechanical Specific Energy (DEMSE) method which indicates that top overpressure occurs in the Gumai Formation.

b) The mechanism of overpressure that occurs at $\mathrm{X}$ is caused by under-compaction, fluid expansion (kerogen maturation).

c) The Gumai Formation and Talang Akar Formation are shale rocks so the type of mud that is well used is oil based mud (OBM).

\section{References}

1. M.A. Budiman, D.D. Warnana, F. Syaifuddin, Kajian, Theoretical Comparison of Pore Pressure Prediction Methods: Eaton Method and Bowers Method, Jurnal Teknik ITS 6(2) (2017)

2. R. Majidi, M. Albertin, N. Last, Method Pore Pressure Estimation Using Drilling Efficiency and Mechanical Specific Energy. IADC/SPE Drilling Conference and Exhibition held in Fort Worth, Texas, USA, 1-3 (2016)

3. D. Ginger, K. Fielding, The Petroleum Systems and Future Potential of The South Sumatra Basin, Proceedings, Indonesian Petroleum Association, Thirtieth Annual Convention \& Exhibition (2005) 
4. R.E. Swarbrick, M.J. Osborne, G.S Yardley, Comparison of Overpressure Magnitude Resulting from the Main Generating Mechanisms, Pressure Regimes in Sedimentary Basin and their Prediction. AAPG 76, 1-12 (2002).

5. M.J Hoesni, Origins of Overpressure in the Malay Basin and Its Influence on Petroleum Systems: Ph.D, Thesis, University of Durham England (2004)

6. G.L. Bowers, Pore Pressure Estimation from Velocity Data: Accounting for Overpressure Mechanisms besides Under Compaction, SPE Drilling \& Completion June (1995).

7. S. Sukmono, Seismic Inversion for Reservoir Characterization, Teknik Geofisika, ITB, Bandung, Indonesia (2000) 